\title{
Ice Box Calorimetry: A useful method for estimating heat discharge rates through steaming ground
}

\author{
Akihiko Terada ${ }^{1}$, Tsuneomi Kagiyama ${ }^{1}$, and Hiromitsu Oshima ${ }^{2}$ \\ ${ }^{1}$ Aso Volcanological Laboratory, Kyoto University, 5280 Kawayo, Minami-Aso, Kumamoto 869-1404, Japan \\ ${ }^{2}$ Usu Volcano Observatory, Faculty of Science, Hokkaido University, 142 Tatsuka, Sobetsu, Hokkaido 052-0106, Japan
}

(Received November 7, 2007; Revised January 20, 2008; Accepted January 22, 2008; Online published July 4, 2008)

\begin{abstract}
We developed a new technique, Ice Box Calorimetry, for estimating heat discharge rates through steaming ground. Ice within an aluminum box provides a powerful tool for measuring the total heat transfer from the ground surface, including conductive heat, convective heat, and latent heat within vapor. Using this method, we are able to rapidly measure heat discharge rates without the need for specialized apparatus. Applying Ice Box Calorimetry to the Nishiyama steaming ground at Usu volcano, Japan in September 2006, we identified local variations in heat discharge rates. The total heat discharged from the entire geothermal area in September 2006 is estimated to be $27 \mathrm{MW}$, which represents just $1 \%$ of the rate immediately following an eruption from the volcano in 2000 .
\end{abstract}

Key words: Ice Box Calorimetry, ice, steaming ground, heat discharge rate, Usu volcano.

\section{Introduction}

Thermal activities such as fumaroles and steaming grounds occur at many volcanoes during non-eruptive periods. Precise estimates of the heat discharge in such areas constrain the mechanism of growth of the hydrothermal system, the cooling process of intruded magma (Matsushima, 2003), and degassing in the magma reservoir and/or conduit (Kazahaya et al., 1994). Energy fluxes from fumaroles are quantitatively estimated using methods such as image analysis (Kagiyama, 1981) and UV spectrometry (Oppenheimer and McGonigle, 2004); however, large uncertainties are involved in estimating energy fluxes from steaming grounds.

The steep temperature gradient commonly encountered in steaming grounds acts to enhance conductive heat transfer. Convective heat transfer and the transfer of latent heat occur simultaneously via diffusive steam discharge through the ground surface. Sekioka and Yuhara (1974) developed the heat balance model to estimate the sum of these heat transfers by IR thermal imaging; however, the method involves large uncertainties because a coefficient in the model varies significantly depending on the volcano of interest and atmospheric conditions (Sekioka, 1983). Directmeasurement methods have also been devised to provide rough estimates of heat transfer (Benseman, 1959; White, 1969). Because the total heat discharge and its temporal variation remain poorly known, for some volcanoes the heat discharge through steaming ground is largely ignored relative to heat discharge from fumaroles.

A significant amount of heat is discharged through steaming ground upon the western flank of Usu volcano, Japan, hereafter referred to as the Nishiyama steaming ground

Copyright (c) The Society of Geomagnetism and Earth, Planetary and Space Sciences (SGEPSS); The Seismological Society of Japan; The Volcanological Society of Japan; The Geodetic Society of Japan; The Japanese Society for Planetary Sciences; TERRAPUB.
(Fig. 1(a), (b)). This area of steaming ground formed immediately after the 2000 eruption (Saba et al., 2007), during which time the ground rose by about $60 \mathrm{~m}$ due to the intrusion of a dyke at a depth of $100 \mathrm{~m}$ (Miura and Niida, 2002). In 2006, the total amount of heat discharged through the steaming ground seems to be larger than that from the remaining fumaroles such as the NB vents (Fig. 1(b)).

The present study focuses on a method of taking reliable measurements of the heat-discharge rate through steaming ground. We propose that ice in an aluminum box is a powerful tool in measuring the total heat transfers, including conductive heat, convective heat, and latent heat within vapor. Using this method, we are able to rapidly evaluate heatdischarge rates without the need for any specialized apparatus (Hochstein and Bromley, 2005). In this paper, we describe the detailed observation procedures and discuss the applicability of this approach based on observations carried out at the Nishiyama steaming ground in 2006.

\section{Heat Budget of Ice on the Ground Surface}

Figure 2 shows a model of heat balance on the ground surface. The ice placed on the steaming ground melts because of the heat flux, including the net incident radiation $R_{n}$, surface heat flux by conduction $C$, surface heat flux by evaporation $E$, and the total geothermal flux from depth $Q$ $\left(\mathrm{W} / \mathrm{m}^{2}\right)$. Here, $Q$ includes conductive heat, convective heat, and latent heat within vapor. The heat balance can be written as

$$
R_{n}-C-E+Q=M
$$

where $M\left(\mathrm{~W} / \mathrm{m}^{2}\right)$ is the heat required to melt the ice. To evaluate the total heat (i.e., $R_{n}, C$, and $E$ ), we placed a thermal insulation mat on the steaming ground surface and put an ice box upon the mat. In this case, the heat required 

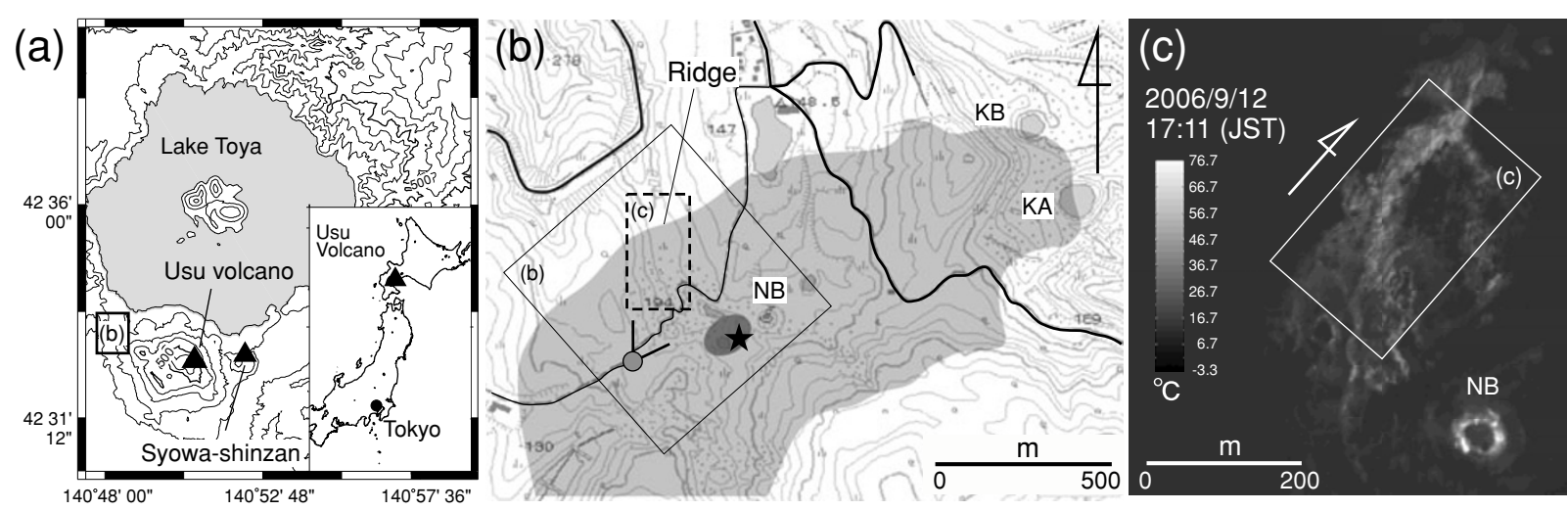

Fig. 1. (a) (b) Map of the Nishiyama steaming ground at Usu volcano. The gray and dark gray areas indicate regions with uplift in excess of 10 and $60 \mathrm{~m}$ in 2000, respectively (Miura and Niida, 2002). The source location of changes in the geomagnetic field is indicated by a star (Hashimoto et al., submitted). Gray solid lines are topographic contours at intervals of $10 \mathrm{~m}$. Bold black solid lines represent vehicle-access roads, and thin black solid lines represent paths accessible only on foot. The photograph shown in Fig. 3(a) was taken at the site indicated by a gray circle. (c) Aerial infrared photograph of the Nishiyama steaming ground, in which non-geothermal areas have been painted out in dark gray.

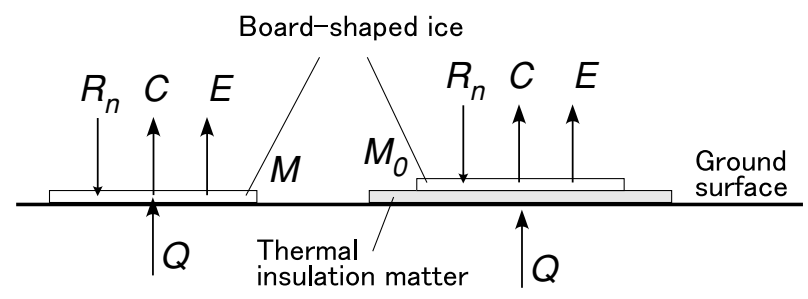

Fig. 2. Heat budget for ice on the ground surface. $R_{n}, C, E, Q$, and $M$ indicate net incident radiation, surface heat flux by conduction, surface heat flux by evaporation, geothermal flux from depth, and the melting heat of ice, respectively.

to melt the ice, $M_{0}$, is written as

$$
R_{n}-C-E=M_{0}
$$

If two ice boxes are located next to each other at the same time (one insulated and one not), we can presume that the thermally insulated ice absorbs as much heat of $R_{n}, C$, and $E$ as the ice box laid directly upon the steaming ground. Consequently, we obtain $Q$ by subtracting Eq. (2) from (1):

$$
Q=M-M_{0}
$$

We can easily measure $M$ and $M_{0}$. The heat necessary to melt the ice $M$ corresponds to the weight of molten water $m(\mathrm{~kg})$ multiplied by the heat of fusion $L(\mathrm{~J} / \mathrm{kg})$ and divided by the surface are of the bottom of the ice $S\left(\mathrm{~m}^{2}\right)$ :

$$
M=\frac{L m}{S t}
$$

where $t$ is the time required to melt $m \mathrm{~kg}$ of ice and $L$ is $3.34 \times 10^{5} \mathrm{~J} / \mathrm{kg}$. Following Eq. (4), we write $M_{0}$ as follows:

$$
M_{0}=\frac{L m_{0}}{S t_{0}}
$$

where $m_{0}$ is the weight of ice melted over $t_{0}$ seconds. In this study, we measure $t, m, t_{0}$, and $m_{0}$ at the steaming ground according to the procedure described below, and calculate $Q$ using Eqs. (3), (4), and (5).

\section{Observations}

Figure 1(c) shows an aerial infrared photograph of the Nishiyama steaming ground taken on 12 September 2006. The steaming area extends over a distance of more than $300 \mathrm{~m}$, within which most of the plants have died due to vapor emissions and maximum temperatures at $10 \mathrm{~cm}$ soil depth of up to $99^{\circ} \mathrm{C}$. In this section, we describe the methodology employed in taking measurements within the steaming ground.

\subsection{Observation tools}

For convenience, we used aluminum boxes $(16 \mathrm{~cm}$ long, $12 \mathrm{~cm}$ wide, $7 \mathrm{~cm}$ high, and $0.8 \mathrm{~mm}$ thickness) with low thermal resistance. We poured $0.1 \mathrm{~kg}$ of water into each box and froze it in a household refrigerator. The boxes produce board-shape blocks of ice of about $5 \mathrm{~mm}$ in thickness. Hereafter, we refer to this aluminum box as the 'Ice Box.' Such aluminum boxes are easily obtained as commercial products manufactured for preserving chilled food.

Corrugated cardboard is useful in insulating the heat flow through the ground. We placed several pieces of corrugated cardboard, wrapped in a plastic bag, on the ground surface for this purpose.

\subsection{Measurements}

Measurements were carried out at the Nishiyama steaming ground on 13-14 September 2006. On both days the weather was fine, with weak winds of less than $1 \mathrm{~m} / \mathrm{s}$, air temperatures of about $20^{\circ} \mathrm{C}$, and relative humidity of about $50 \%$. No precipitation was observed in the week leading up to the measurements.

The observations were carried out upon ground within which the temperatures at $10 \mathrm{~cm}$ depth ranged from 30 to $99^{\circ} \mathrm{C}$. With reference to Fig. 1(c), we located 28 measurement sites along a ridge at 10-30 m intervals (Fig. 3(a), Fig. 4). On 13 September, we measured $M$ at 15 sites and $M_{0}$ at 3 sites; on 14 September, we measured $M$ at 17 sites and $M_{0}$ at 3 sites.

\subsection{Measurement procedure}

The photograph in Fig. 3(b) shows an example of the measurement set-up. We placed the Ice Box on the ground after leveling the surface using our feet. We removed any water from the aluminum box that accumulated as a result 

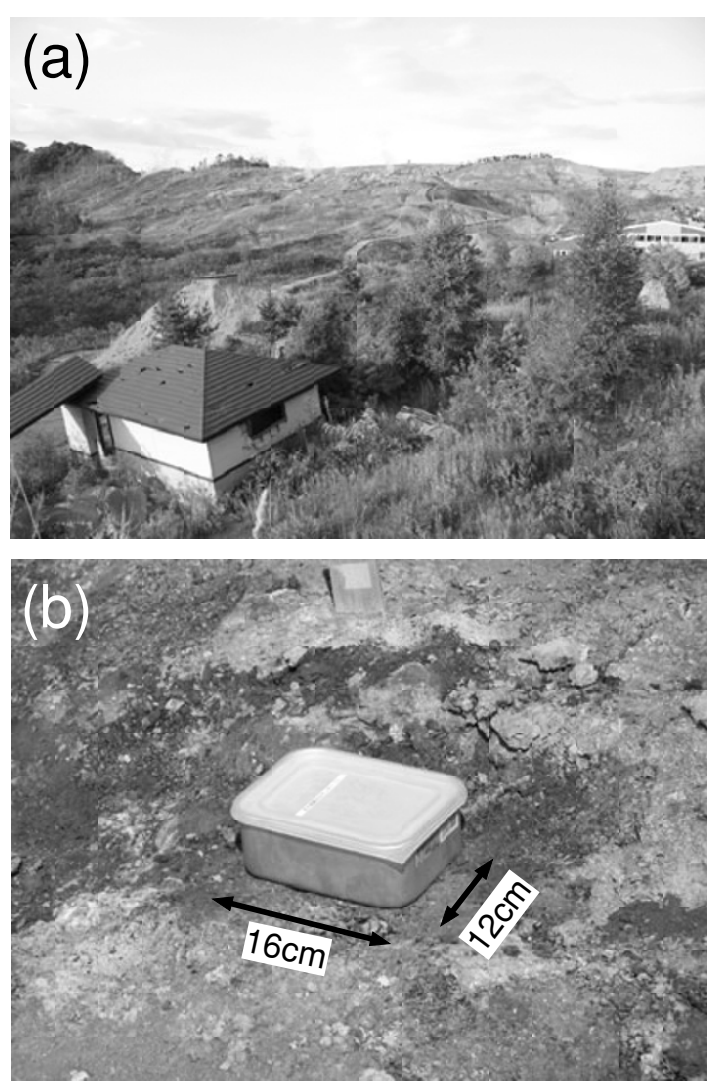

Fig. 3. (a) View of the ridge in the central area of the Nishiyama steaming ground. This image was taken from the site indicated by the gray circle in Fig. 1(b). (b) Example of the placement of the Ice Box at site U5.

of the ice melting prior to placing the box on the ground. After several minutes $t$ (e.g. 5 minutes), as measured using a stopwatch, we picked up the Ice Box and measured the water volume with a beaker, thereby obtaining the mass of molten water $m$.

To measure $M_{0}$, we placed a second Ice Box on the insulation mat close to the original measurement site; we also obtained $t_{0}$ and $m_{0}$ following the same procedure. For greater accuracy, measurements of $M_{0}$ should be carried out at each measurement site at the same time as measurements of $M$. Because temporal and spatial inhomogeneities in $E$ and $C$ are smoothed by the ambient wind, we consider that it is not necessary to measure $M_{0}$ at exactly the same site as that for $M \mathrm{~s}$ '. For convenience, measurements of $M_{0}$ were carried out every $100 \mathrm{~m}$ and every $30 \mathrm{~min}$ because atmospheric conditions, including temperature and sunlight, were stable. Double circles in Fig. 4 indicate the locations of measurement sites for $M_{0}$. Hereafter, we refer to the above technique as 'Ice Box Calorimetry' (IBC).

\subsection{Laboratory experiments}

To assess the applicability of IBC, we carried out a laboratory experiment using a hotplate upon which we placed a $25 \mathrm{~mm}$ thickness of wet sand. We used IBC to measure $m$, $t, m_{0}$, and $t_{0}$, and calculated a $Q$ value of $0.6-2.6 \mathrm{~kW} / \mathrm{m}^{2}$ for a surface hotplate temperature of $100^{\circ} \mathrm{C}$. The results of the experiments demonstrate that the value of $Q$ s estimated by IBC corresponds to the heat flows calculated from the power consumption of the hotplate.

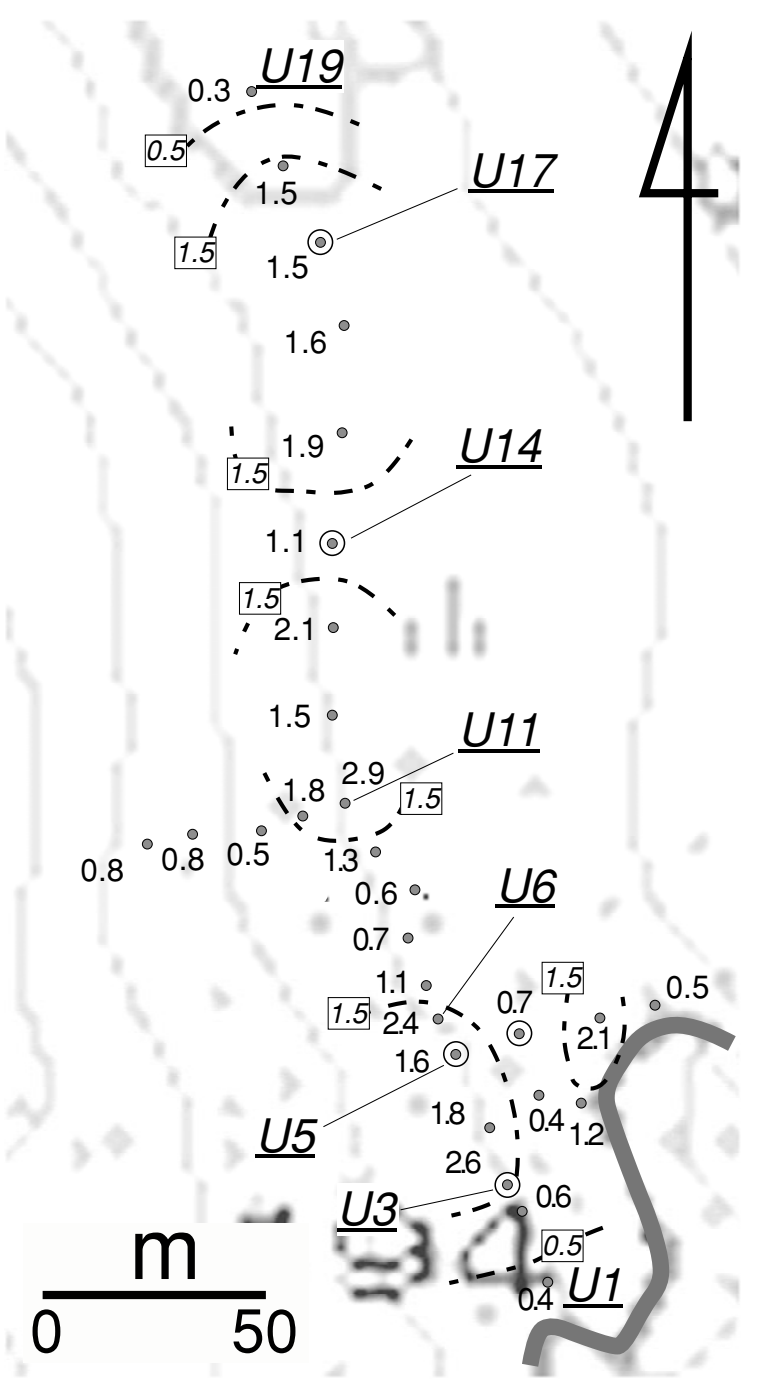

Fig. 4. Distribution of IBC measurement sites and geothermal heat fluxes $Q\left(\mathrm{~kW} / \mathrm{m}^{2}\right)$. Dashed lines represent contours of the heat-discharge rate at intervals of $1.0 \mathrm{~kW} / \mathrm{m}^{2}$. See the text for details.

\section{Heat-discharge Rates from the Nishiyama Steaming Ground}

\subsection{Measurement results}

Figure 4 shows the obtained spatial distribution of $Q$. Estimated values of $Q$ s range from 0.40 to $2.89 \mathrm{~kW} / \mathrm{m}^{2}$. The contour pattern reveals three dominant areas of heat discharge; these areas correspond to sites of vigorous steam production.

To assess the reproducibility of estimates calculated using IBC, we recorded measurements at the same sites (U3, U5, and U6; Table 1) on both 13 and 14 September; atmospheric conditions were similar on both days. At site U5, the variance of three measured values of $Q$ was less than $5 \%$, although large differences in $Q$ were recorded at sites $\mathrm{U} 3$ and U6, probably resulting from slight differences in the locations of the Ice Boxes or temporal changes in vapor emissions.

\subsection{Estimates of total heat flux}

Figure 5 shows the relationship between $Q$ and the temperature anomaly at the ground surface, $T$ minus $T_{0}$, based on aerial infrared photograph (Fig. 1(c)). Here, $T_{0}$ is the 
Table 1. Selected results of measured and computed parameters. $T_{10}$ is the temperature at $10 \mathrm{~cm}$ depth, $t_{0}$ is the time required to melt $m_{0}$ of ice located upon an insulation mat, and $t$ is the time required to melt $m$ of ice upon steaming ground. $M_{0}, M$, and $Q$ were computed using Eqs. (4), (5), and (3), respectively. Sites with asterisks indicate results for 14 September 2006.

\begin{tabular}{|c|c|c|c|c|c|c|}
\hline Site & $\begin{array}{l}T_{10} \\
{ }^{\circ} \mathrm{C} \\
\end{array}$ & $\begin{array}{c}m_{0} \\
\mathrm{~g}\end{array}$ & $\begin{array}{c}t_{0} \\
\mathrm{sec}\end{array}$ & $\begin{array}{c}M_{0} \\
\mathrm{~kW} / \mathrm{m}^{2}\end{array}$ & & \\
\hline $\mathrm{u} 5^{\prime}$ & 94.3 & 55 & 900 & 1.06 & & \\
\hline u5 & 94.3 & 70 & 1,005 & 1.21 & & \\
\hline \multirow[t]{2}{*}{ u3* } & 99.4 & 57 & 960 & $1.03^{*}$ & & \\
\hline & $\begin{array}{l}T_{10} \\
{ }^{\circ} \mathrm{C} \\
\end{array}$ & $\begin{array}{r}m \\
\mathrm{~g}\end{array}$ & $\begin{array}{c}t \\
\mathrm{sec}\end{array}$ & $\begin{array}{c}M \\
\mathrm{~kW} / \mathrm{m}^{2}\end{array}$ & $\begin{array}{c}Q \\
\mathrm{~kW} / \mathrm{m}^{2}\end{array}$ & Reference \\
\hline U3 & 99.4 & 97.5 & 420 & 4.04 & 2.83 & u5 \\
\hline U3* & 99.4 & 82 & 420 & 3.40 & $2.36^{*}$ & u3* \\
\hline U5 & 94.3 & 65 & 420 & 2.69 & 1.63 & u $5^{\prime}$ \\
\hline U5 & 94.3 & 60 & 386 & 2.70 & 1.49 & u5 \\
\hline U5* & 94.3 & 72 & 480 & 2.61 & $1.58^{*}$ & u3* \\
\hline U6 & 98.6 & 95 & 405 & 4.08 & 2.87 & u5 \\
\hline U6* & 98.6 & 86 & 510 & 2.93 & $1.90^{*}$ & u3* \\
\hline
\end{tabular}

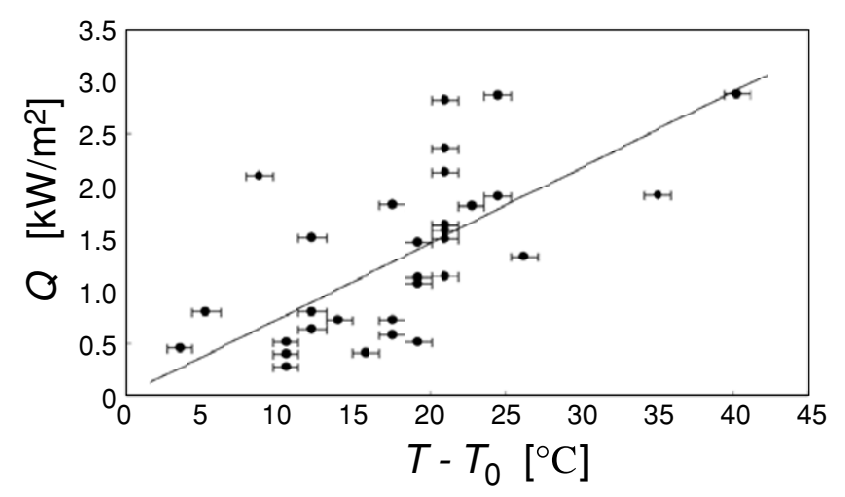

Fig. 5. Plot of $Q$ vs. $T-T_{0}$, as estimated from the aerial infrared photograph. The range in each temperature rank within the infrared photograph is indicated by horizontal error bars on each data point.

ground surface temperature outside of the geothermal area. In Fig. 1(c), temperatures are classified into 25 ranks (every $2.5^{\circ} \mathrm{C}$ ) and expressed using a gray scale. In this study, $T_{0}$ and $T_{i}$ represent the median temperatures of each rank. The large scatter of data in Fig. 5 probably reflects the poor resolution of the infrared photograph and the misfit of site locations on the photograph.

Using the relation obtained from Fig. 5, we can easily estimate the total heat flux across the entire Nishiyama steaming ground. Assuming a linear relationship between $Q$ and the temperature anomaly $T-T_{0}$, the total heat discharge rate $G$ is calculated by the following equation:

$$
G=C \sum_{i}\left(T_{i}-T_{0}\right) S_{i}
$$

where $T_{i}$ is the $i$-th temperature rank on the infrared photograph and $S_{i}$ is the surface area of $T_{i}$ calculated using the known parameter of $3.24 \mathrm{~m}^{2} /$ pixel. The total measurement area is $2.9 \times 10^{4} \mathrm{~m}^{2}$, as estimated by summing $S_{i}$. Applying a least squares method to the relationship obtained from Fig. 5, we obtain a constant $C$ of $73 \mathrm{~W} / \mathrm{K} / \mathrm{m}^{2}$.

Applying Eq. (6) to the infrared photograph (Fig. 1(c)), the total heat discharge rate across the entire Nishiyama steaming ground is estimated to be $16 \mathrm{MW}$. The range of each temperature rank in Fig. 1 (c) is $2.5^{\circ} \mathrm{C}$. If we apply the minimum temperature of rank $T_{0}$ to Eq. (6), the total heat discharge rate is estimated to be $19 \mathrm{MW}$; if we use the maximum temperature of $\operatorname{rank} T_{0}$, the estimate is $14 \mathrm{MW}$.

\section{Discussion}

\subsection{Features of the IBC method}

We developed a new technique, Ice Box Calorimetry, which readily measures the heat discharge rate through steaming grounds without the need for any specialized apparatus. Applying IBC to the Nishiyama steaming ground at Usu volcano, Japan, we obtained both local variations in the heat discharge rate and the total rate.

IBC can be used to measure both the conductive and convective heat discharge rates from the ground surface. Volcanic gas discharged from the ground surface comes into immediate contact with the bottom of the Ice Box, which thereby receives sensible heat. Simultaneously, latent heat generated by the condensation of vapor in the gas is transferred to the Ice Box.

Maintaining the ice temperature at around $0^{\circ} \mathrm{C}$ is useful when heat measurements. Most of the emitted gases do not pass around the Ice Box because of the volume deflation of vapor arising from its condensation at $0^{\circ} \mathrm{C}$. In addition, most of the latent heat in vapor can be measured because vapor is largely condensed at $0^{\circ} \mathrm{C}$. Despite this, the amount of gas that passes around the Ice Box is likely to increase with increased vapor flux from the ground surface. The results of our laboratory experiment confirmed that the heat discharge rates $Q$ estimated by IBC are valid for rates less than $2.6 \mathrm{~kW} / \mathrm{m}^{2}$ at least.

It is difficult to control the sensor temperature of commercial heat-flow meters at temperatures of $0^{\circ} \mathrm{C}$. Given that temperature at the bottom of Ice Box is automatically set close to $0^{\circ} \mathrm{C}$, ice is a powerful tool in evaluating heat flow in a vapor-rich field. We can easily compare $Q$ with those values measured at different air temperatures or even at different volcanoes.

IBC measures heat transfer from the ground surface to ice, yet under natural conditions the heat is transferred to the atmosphere. Within areas of steaming ground, the con- 
vection of vapor plays an important role in heat transfer (Hochstein and Bromley, 2005). Thus, given that the size of the block of ice placed on the ground is much smaller than that of the steaming ground, placing the ice on the ground has no affect on vapor emissions. We therefore conclude that IBC yields almost the same heat discharge rate as that under natural conditions. In areas dominated by conductive heat, where little vapor is emitted, the low-temperature Ice Box leads to a reduction in ground surface temperature, thereby enhancing conductive heat flow. In such a case, the IBC method may yield larger $Q$ values than those under natural conditions.

In Section 4.2, we assumed a linear relationship between the heat discharge rate $Q$ and ground surface temperature $T$, and estimated the total heat flux from Eq. (6). This model corresponds to the heat balance model of Sekioka and Yuhara (1974). Sekioka (1983) reported that the coefficient of the heat balance model varies across the range from 16 to $92 \mathrm{~W} / \mathrm{K} / \mathrm{m}^{2}$ for thermal conditions, thereby complicating any attempt at observations. Using IBC and IR images, the relationship between $Q$ and $T$ obtained from several sites could be used to assess the reliability of the coefficient of the heat balance model.

The application of IBC to many different volcanoes could provide information on the heat budgets of volcanoes and differences in magma-hydrothermal systems at different volcanoes.

\subsection{Implications for the cooling process of intruded magma}

The total heat discharge rate across the entire Nishiyama steaming ground is estimated to be $16 \mathrm{MW}$. Terada et al. (submitted) reported that the heat discharge rates from the fumarole of the NB vent, from the surface of the KA crater lake, and through the steaming ground around the KA vent (Fig. 1(b)) are approximately 8, 2, and $0.7 \mathrm{MW}$, respectively; consequently, the total heat discharge rate from the entire region is approximately $27 \mathrm{MW}$.

Significant linear geomagnetic variations have been observed in the area around the Nishiyama steaming ground. Assuming these changes reflect cooling of the intruded magma body, one of the centers of the magnetizing sources is required to be located at the star in Fig. 1(b), at a depth of $500 \mathrm{~m}$. The relevant heat loss is roughly estimated to be 60-120 MW per second (Hashimoto et al., submitted). The heat-loss rate estimated using the simple point-source model appears to be inconsistent with the heat discharge rate measured from the ground surface.

Immediately following the 2000 eruption, the heat discharge rate from the Nishiyama region was more than 2,000 MW (Goto et al., 2007), although this rate had decreased significantly by September 2006 . For the next-most recent eruption at Usu volcano in 1977, when the volume of intruded magma was similar to that in 2000, Matsushima (2003) reported a gradual increase in the heat discharge rate through steaming ground after the eruption, and a gradual decrease after 1980. The differences in geothermal activity between the 2000 and 1977 eruptions may reflect the contrasting development of the magma-hydrothermal system: magma intruded at the summit area in 1977 and upon a flank area in 2000 , probably reflecting differences in un- derground conditions such as permeability and groundwater level.

Given that previous estimates of heat discharge rates through steaming ground have been somewhat inaccurate, the relatively accurate observations afforded by IBC are valuable in enabling more detailed discussions of heat discharge rates.

Acknowledgments. We are grateful to the staff of Usu Volcano Observatory, Hokkaido University, staff of the Japan Meteorological Agency, and Shin Yoshikawa for their assistance with fieldwork. We thank Takeshi Hashimoto, Yoshiaki Ida, Nobuo Matsushima, and Hiroshi Shinohara for their valuable comments and discussions. We are also grateful to Tony Hurst for polishing the English in the manuscript. Constructive comments by two anonymous reviewers led to substantial improvements to the manuscript. This work was supported by Kyoto University Active Geosphere Investigations for the 21st Century Centers of Excellence Program (KAGI21), which was approved by the Ministry of Education, Culture, Sports, Science, and Technology (MEXT) of Japan.

\section{References}

Benseman, R. F., The calorimetry of steaming ground in thermal areas, $J$. Geophys. Res., 64, 123-126, 1959.

Goto, A., T. Kagiyama, T. Miyamoto, A. Yokoo, and H. Taniguchi, Longterm prediction of Usu volcano 2000 eruptive activity based on the measurements of heat discharge rate, Geoph. Bull. Hokkaido Univ., 70, 137-144, 2007 (in Japanese with English abstract).

Hashimoto, T., T. Hurst, A. Suzuki, T. Mogi, Y. Yamaya, and M. Tamura, The role of Thermal Viscous Remanent Magnetisation (TVRM) in magnetic changes associated with volcanic eruptions: insights from the 2000 eruption of Mt Usu, Japan, J. Volcanol. Geotherm. Res., (submitted).

Hochstein, M. P. and C. J. Bromley, Measurement of heat flux from steaming ground, Geothermics, 34, 131-158, 2005.

Kagiyama, T., Evaluation methods of heat discharge and their applications to the major active volcanoes in Japan, J. Volcanol. Geotherm. Res., 9, 87-97, 1981.

Kazahaya, K., H. Shinohara, and G. Saito, Excessive degassing of IzuOshima Volcano-Magma convection in a conduit, Bull. Volcanol., 563, 207-216, 1994.

Matsushima, N., Mathematical simulation of magma-hydrothermal activity associated with the 1977 eruption of Usu volcano, Earth Planets Space, 55, 559-568, 2003.

Miura, D. and K. Niida, Two-stage growth model of cryptodome by shallow intrusions, the 2000 eruption of Usu volcano, northern Japan, Bull. Vol. Soc. Japan, 47, 119-130, 2002 (in Japanese with English abstract). Oppenheimer, C. and A. J. S. McGonigle, Exploiting ground-based optical sensing technologies for volcanic gas surveillance, Ann. Geophys., 47, 1455-1470, 2004.

Saba, M., Y. Nishida, T. Mogi, S. Takakura, and N. Matsushima, Development of geothermal field following the 2000 eruption of Usu volcano as revealed by ground temperature, resistivity and self-potential variations, Ann. Geophys., 50, 79-92, 2007.

Sekioka, M., Proposal of a convenient version of the heat balance technique estimating heat flux on geothermal and volcanic fields by means of infrared remote sensing, Memoirs of the National Defense Academy Japan, 23, 95-103, 1983.

Sekioka, M. and K. Yuhara, Heat flux estimation in geothermal areas based on the heat balance of the ground surface, J. Geophys. Res., 79(14), 2053-2058, 1974.

Terada, A., H. Oshima, N. Matsushima, and T. Kagiyama, Quantitative evaluation of heat discharge rates from the geothermal area formed during the 2000 eruption of Usu volcano, Japan: Comparison with magma cooling processes following the 1977 eruption, J. Geotherm. Res. Soc. Japan, submitted (in Japanese with English abstract).

White, D. E., Rapid heat-flow surveying of geothermal areas, utilizing individual snowfalls as calorimeters, J. Geophys. Res., 74, 5191-5201, 1969.

A. Terada (e-mail: terada@aso.vgs.kyoto-u.ac.jp), T. Kagiyama, and H. Oshima 